4. Abouzeid $\mathbf{H}$, Wolfensberger $\mathbf{T J}$. Macular recovery after retinal detachment. Acta Ophthalmol Scand. 2006; 84(5):597-605. doi:10.1111/j.16000420.2006.00676.X

5. Delolme MP, Dugas B, Nicot F, Muselier A, Bron AM, Creuzot-Garcher C. Anatomical and Functional Macular Changes After Rhegmatogenous Retinal Detachment With Macula Off. Am J Ophthalmol. 2012;153(1):128-136. doi:10.1016/ j.ajo.2011.06.010

6. Joe SG, Kim YJ, Chae JB, et al. Structura recovery of the detached macula after retinal detachment repair as assessed by optical coherence tomography. Korean J Ophthalmol KJO.
2013;27(3):178-185.

doi:10.3341/kjo.2013.27.3.178

7. Seo JH, Woo SJ, Park KH, Yu YS, Chung H. Influence of Persistent Submacular Fluid on Visual Outcome After Successful Scleral Buckle Surgery for Macula-off Retinal Detachment. Am J Ophthalmol. doi:10.1016/j.ajo.2008.01.005 2008;145(5):915-922.e1.

8. Wolfensberger TJ, Gonvers $\mathbf{M}$. Optical coherence tomography in the evaluation of incomplete visual acuity recovery after macula-off retinal detachments. Graefes Arch Clin Exp Ophthalmol. 2002;240 (2):85-89. doi:10.1007/ s00417-001-0410-6

\title{
THUỐC UỐNG DÙNG CHO TRẺ EM
}

\section{TÓM TẮT}

Việc nghiên cứu phát triển các công thức thuốc uống dùng cho trẻ em đang là vấn đề thách thức đối với các nhà nghiên cứu bào chế. Khó khăn lớn nhất đối với các dạng bào chế này là liều dùng tính theo cân nặng và phải hạn chế được mùi vị khó chịu. Hiện nay, các chế phẩm thuốc uống dùng cho trẻ em có thể là dạng bào chế có sẵn hoặc phải thao tác trước khi sử dụng. Các chế phẩm có thể dùng ngay bao gồm dung dịch uống, si rô, hốn dịch thuốc, viên nén, viên nén mini, viên nhai, viên nén phân tán trong miệng, màng phim hòa tan trong miệng. Các chế phẩm phải thao tác trước khi sử dung bao gồm bôt pha dung dịch hoặc hỗn dịch, viên phân tán tạo hốn dich, viên sủi bọt, viên nén mini hoăc viên nang chứa bột có thể trộn với đồ ăn hoăcc đồ uống. Bài báo này trình bày các dạng bào chế dùng đường uống cho trẻ em. Bài báo cũng đưa ra những tiến bộ mới trong việc phát triển các dạng bào chế dùng cho trẻ em và dụng cụ phân liều đường uống dùng cho trẻ em.

Tư khóa: thuốc, trẻ em, uống

\section{SUMMARY \\ PEDIATRIC ORAL FORMULATIONS}

Pediatric oral formulations can be quite scientifically challenging to develop. The prerequisites for both a measurable dosage form to administer based upon bodyweight, and also taste-masking are two of the challenges for pediatric oral formulations. Oral pediatric formulations are available in some different varieties and can be either a ready-to-use formulation or require manipulation. Ready-to-use formulations include oral solution, syrup, suspension, tablets, mini-tablets, chewable tablet, orally disintegrating tablet, oral soluble films. Formulations requiring manipulation include oral powder for

*Trường Đại hoc Dược Hà Nội

Chịu trách nnhiệm chính: Dướng Thị Hồng Ánh

Email: anhdth@hup.edu.vn

Ngày nhân bài: 5.01 .2021

Ngày phản biên khoa hoc: 5.3.2021

Ngày duyệt bài: 15.3.2021

\section{Dương Thị Hồng Ánh*}

constitution to a solution or suspension, tablet for constitution to a suspension, effervescent tablet, minitablet or powder in a capsule to mix with food or drink. In this article, the various types of formulations administered orally to pediatrics are presented. This paper also provides some recent progress in the development of pediatric formulations and delivery devices for pediatric oral administration.

\section{GIỚI THIÊU CHUNG}

Theo phân loại của Tổ chức $Y$ tế Thế giới (WHO), trẻ em được tính từ lúc mới sinh đến khi 18 tuổi, trong đó các nhóm tuổi cần có những lưu ý đặc biệt là: Sơ sinh (từ 0 đến 28 ngày tuổi), nhũ nhi (1-12 tháng tuổi) và trẻ em (1-12 tuổi). Trẻ em không phải là người lớn thu nhỏ vì có nhiều đặc điểm giải phẫu, sinh lý, tâm lý, bệnh lý... khác xa người lớn. Do đó, hấp thu, phân bố, chuyến hóa, thải trừ thuốc ở trẻ em có nhiều đặc điểm mà các nhà nghiên cứu bào chế phải lưu ý khi nghiên cứu xây dựng công thức thuốc dùng cho trẻ em.

Hiện nay, các dạng bào chế thuốc thường chỉ được thiết kế dành cho người lớn, không dành riêng cho trẻ em, gây khó khăn trong việc sử dụng. Điều này có thể dẫn đến việc khó xác định dược động học của các loại thuốc do chưa được nghiên cứu đầy đủ trên trẻ em hoặc lựa chọn thuốc không thích hợp cho trẻ em. Chính vì vậy, việc nghiên cứu các dạng bào chế thích hợp dùng cho trẻ em là vấn đề cấp thiết. Trong đó, đường uống là đường dùng phổ biến và thích hợp nhất cho trẻ em. Bài báo này trình bày tóm tắt một số dạng bào chế và hệ phân phối thuốc dùng qua đường uống cho trẻ em và một số hướng nghiên cứu về bào chế thuốc uống dùng cho trẻ em hiện nay.

\section{BÀO CHẾ THUốC UỐNG CHO TRẺ EM}


Thuốc uống là dang bào chễ được các nhà sản xuất lựa chọn để tạo ra dạng bào chế thích hợp với trẻ em. Các dạng bào chế dùng đường uống thích hợp dành cho trẻ em vẫn còn chưa được nghiên cứu đầy đủ do nguyên nhân chủ yếu liên quan đến liều lượng, khả năng nuốt, mùi vị và tính an toàn của tá dược khi sử dụng trong chế phẩm cho trẻ em. Bảng 1 liệt kê một số dạng bào chế dùng đường uống thích hợp cho trẻ em theo từng độ tuổi [7].

Bảng 1. Một số dạng bào chế dùng đường uống thích hợp cho trẻ em

\begin{tabular}{|c|c|c|c|}
\hline Nhóm & Tuổi & $\begin{array}{l}\text { Cân năgng } \\
\text { (kg) }\end{array}$ & Dạng bào chế thích hợp \\
\hline $\mathrm{Si}$ & - & $<3$ & $\begin{array}{l}\text { Ông xông vào dạ dày } s \\
\text { thuốc, bột hoặc cốm ph }\end{array}$ \\
\hline Trẻ & $\begin{array}{r}0-28 \\
t\end{array}$ & 3-5 & $\begin{array}{r}\text { Dung dịch hoặc hồ } \\
\text { dịch }\end{array}$ \\
\hline $\begin{array}{l}\text { Trẻ } \\
\text { trẻ }\end{array}$ & $\begin{array}{r}1 \text { tha } \\
\text { tu }\end{array}$ & $5-10$ & $\begin{array}{r}\text { Dung dịch, hồn dịch thuốc, viên n } \\
\text { tán nhanh trong }\end{array}$ \\
\hline Trẻ & 2 & $10-25$ & $\begin{array}{r}\text { Viên nén mini, viên } \\
\text { cốm di }\end{array}$ \\
\hline Trẻ tiểu học & 6-12 tuối & $20-40$ & Viên nhai, viên nén phân tán nhanh trong miệng \\
\hline
\end{tabular}

Các thuốc dùng đường uống thích hợp cho trẻ em có thể là dạng bào chế sử dụng ngay như si rô, hỗn dịch, viên nén, viên nén mini, viên nhai, viên phân tán trong miệng, màng phim tan trong miệng hoặc cũng có thế là một dạng bào chế yêu cầu phải thao tác trước khi sử dụng như bột pha dung dịch, hỗn dịch, viên sủi bọt, viên nang chứa bột rắc vào thức ăn và đồ uống...

\section{THUỐc UỐNG SỬ DỤNG NGAY}

Thuốc uống dạng lỏng. Các dạng bào chế thuốc lỏng uống sử dụng ngay thường bao gồm dung dịch thuốc, hỗn dịch thuốc, nhũ tương thuốc, elixir, si rô thuốc... Các dạng thuốc này có ưu điểm dể nuốt, đặc biệt đối với trẻ sơ sinh (đến 28 ngày tuối), trẻ sơ sinh và trẻ mới biết đi ( 1 tháng đến 23 tháng) và trẻ nhỏ (dưới 6 tuổi). Măc dù vây, chúng cũng tồn tại một số nhược điểm khiên việc sử dụng thuốc ở trẻ em trở nển khó khăn.

Thứ nhất là vấn đề mùi vị: Mùi vị được nhận biết thông qua sự kích thích của một tập hợp khoảng 50 đến 100 tế bào thụ cảm chuyên biệt nằm trong các chồi vị giác trên biểu mô của lưỡi và khoang miệng. Khoang miệng cảm nhận các vị khác nhau: ngọt, chua, mặn, đắng và mặn. Trẻ em thường nhạy cảm với vị đắng và không quen thuộc của thuốc nhiều hơn người lớn. Mùi vị đã được thừa nhận là một lý do phổ biến khiến trẻ em không tuân thủ. Phần lớn các loại thuốc kháng sinh dùng đường uống thường có vị đắng, đây là khó khăn khi sử dụng cho đối tượng trẻ em.

Để đánh giá mùi vị của thuốc, một số nghiên cứu gần đây đã sử dụng lưỡi điện tử và bảng cảm nhận của con người, đặc biệt là những thuốc sử dụng ở trẻ em. Lưỡi điện tử là một cảm biến hương vị mô phỏng nhận thức của con người thông qua ma trận các cảm biến hóa học và xử lý dữ liệu thống kề. Hệ thống này bao gồm các màng của đầu dò để thu nhận hương vị và một bộ chuyển đổi tín hiệu cung cấp kết quả. Một số cảm biến điện tử được sử dụng để đánh giá mùi vị, sử dụng các nguyên tẳc đo lường khác nhau, chẳng hạn như đo điện thế, đo điện thế, trở kháng và kỹ thuật phát khối quang học.

Thứ hai là vấn đề sử dụng tá dược: Một trong những vấn đề thách thức khi thiết kế công thức thuốc dùng cho bệnh nhi là sàng lọc và lựa chọn cẩn thận các tá dược. Lý do là một số tá dược được sử dụng an toàn trong các công thức dành cho người lớn (ví dụ: alcol benzylic, ethanol, propylen glycol, các paraben) nhưng lại có bằng chứng liên quan đến nguy cơ độc tính cao và các vấn đề an toàn khi sử dụng cho trẻ em, ngay cả ở nồng độ thấp. Mặc dù vậy, các tá dược này vẫn có mặt trong nhiều loại thuốc thường được sử dụng. Do đó, đánh giá toàn diên về độ an toàn của các tá dược trong chế phẩm dành cho trẻ em là điều cần thiết.

Ví du: Ethanol không được có mặt trong các sản phẩm dành cho trẻ em, nhưng nểu được yêu cầu vì mục đích hòa tan, chế phẩm không được chứa quá $5 \%$ ethanol. Nhiều loại thuốc dùng cho trẻ em trên thị trường hiện nay chứa ethanol với nồng độ cao hơn 5\%. Ví dụ: dung dịch uống methadon $(8 \%$ ethanol) và elixir phenobarbital (15\% ethanol) nhưng lại được sử dụng phổ biến cho trẻ sơ sinh.

Thứ ba là dụng cụ phân liều. Thể tích liều dùng thường là không quá $5 \mathrm{ml}$ đối với trẻ em dưới 5 tuổi và không quá $10 \mathrm{ml}$ đối với trẻ em từ 5 tuổi trở lên. Do đó, đối với các dạng thuốc 
lỏng, các vạch chia phải rõ ràng để cho phép lấy ra liêuu thuốc chính xác. Theo Học viện Nhi khoa Hoa Kỳ, việc sử dụng xilanh dùng đường uống có độ chính xác cao hơn so với thìa, cốc chia vach và có thể điều chỉnh được liều thuốc dễ dàng. Ngoài ra, xilanh uống có thể giúp khắc phục các vấn đề về mùi vị vì phần đầu xilanh tương đối nhỏ [4].

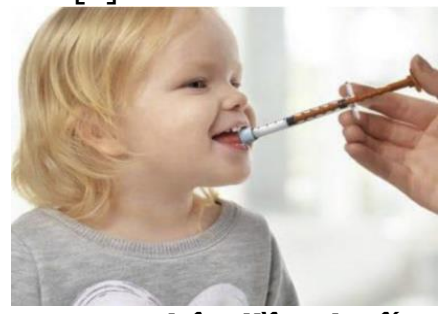

\section{Hình 1. Dụng cụ phân liều thuốc uống dạng lóng bằng xilanh}

Bên cạnh đó, thuốc uống dạng lỏng thường cồng kềnh, khó vận chuyển và cần các điều kiện bảo quản thích hợp. Ở trạng thái lỏng, dược chất có thể phản ứng với tá dược, đồng thời dễ bị vi sinh vật phát triển. Do đó, dạng bào chế lỏng có hạn sử dụng thường thấp hơn so với dạng bào chế rắn.

Thuốc uống dạng rắn. Dạng bào chế rắn có một số ưu điểm so với dạng lỏng như không yêu câuu bảo quản đặc biệt, liều lượng được điêuu chỉnh và dể sử dụng. Viên nén, viển nang, bột có thể tích gọn nhẹ, dễ vận chuyển. Tuy nhiên, thuốc uống dạng rắn có thể khó nuốt và thường có mùi vị khó chấp nhận. Ngoài ra, việc sử dụng các chế phẩm rắn ở trẻ em còn phụ thuộc độ tuổi của trẻ, kích thước, hình dạng, kết cấu và độ cứng [5].

Để khắc phục vấn đề này, một số dạng bào chế rắn như viên nén nhỏ, viên nén mini, viên nén phân tán nhanh trong miệng, viên nén nhai... đã được sản xuất thành chế phẩm thương mại và thích hợp dùng cho trẻ em. Viên nén và viển nén mini phân tán trong miệng đã được Comoglu T. và cộng sự nghiên cứu bào chế [2]. Viên phân tán trong miệng được biết đến là hệ thống phân phối thuốc phù hợp, đặc biệt là đối với bệnh nhi, vì đặc tính phân tán nhanh, sử dụng không cần nước và không gây khó khăn khi nuốt. Viên nén mini phân tán trong miệng kết hợp các đặc tính ưu việt của viên nén phân tán trong miệng và kích thước nhỏ của viên nén mini, nhằm mục đích sử dụng cho trẻ em. Những viên nén mini có đường kính 2-4mm, được bào chế với hương vị có thể chấp nhận được cho trẻ em. Ví dụ: viên nén mini Orfiril (acid valproic) hoặc Enzym Lefax forte (pancreatin) của Bayer Vital $\mathrm{GmbH}$ Geschaftsbereich Pharma, Đức).

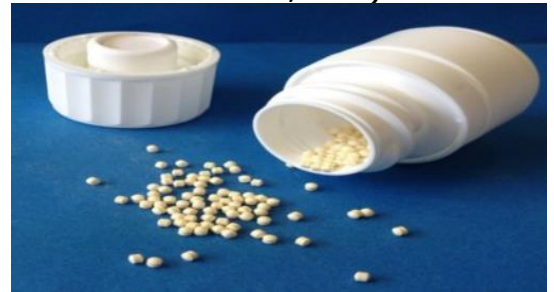

Hình 2. Hình ảnh viên nén mini

Thuốc uống dạng khác. Một dạng bào chế khác là màng phim phân tán trong miệng. Đó là một màng polyme tan trong nước có thể tan nhanh trong miệng. Zuplenz $®$ (ondansetron) màng tan trong miệng của Strativa Pharmaceuticals có tác dụng ngăn ngừa buồn nôn và nôn do hóa trị, xạ trị hoặc buồn nôn sau phẫu thuật với liều đớn vị $4 \mathrm{mg}$ hoặc $8 \mathrm{mg}$ cho một liều lượng một phim $4 \mathrm{mg}$. Phim được dán trền đầu lưỡi, tan trong 4 đến 20 giây và sau đó được nuốt bằng nước bọt và không cần nước để giúp hòa tan hoặc nuốt.

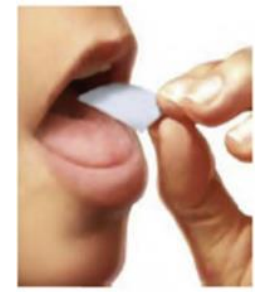

Hình 3. Cách sử dụng màng phim tan trong miệng Bảng 2 liệt kê một số chế phẩm thương mại sử dụng ngay cho trẻ em qua đường uống.

\begin{tabular}{|c|c|c|c|}
\hline Dạng bào chế & Tên thương mại & Dược chất & Hãng sản xuất \\
\hline \multirow{4}{*}{ Dung dịch uống } & Epidiolex® & Cannabidiol & Greenwich Bio-sciences, Inc. \\
\hline & Desitrend $\mathbb{R}$ & Levetiracetam & Desitin Pharmaceuticals GmbH \\
\hline & Zofran $\AA$ & Ondansetron $\mathrm{HCl}$ & GlaxoSmithKline \\
\hline & Hemangeol $\AA$ & Propranolol $\mathrm{HCl}$ & Pierre Fabre Pharmaceuticals, Inc. \\
\hline \multirow{4}{*}{ Hỗn dịch uống } & Onfiß & Clobazam & \\
\hline & Felbato $\AA$ & Felbamat & Meda Pharmaceuticals \\
\hline & Purixan $\AA$ & Mercaptopurin & Rare Disease Therapeutics, Inc. \\
\hline & Noxafil@ & Posaconazol & Merck \\
\hline
\end{tabular}


TAP CHÍ Y HỌC VIÊT NAM TẬP 500 - THÁNG 3 - SỐ 2 - 2021

\begin{tabular}{|c|c|c|c|}
\hline $\begin{array}{l}\text { Màng phim hòa } \\
\text { tan trong miệng }\end{array}$ & Zuplenz® & Ondansetron & Strativa Pharmaceuticals \\
\hline Viên nén & Banzel@ & Rufinamid & Eisai \\
\hline $\begin{array}{l}\text { Viên nén phân } \\
\text { tán trong miệng }\end{array}$ & Zofran ODT $®$ & Ondansetron & GlaxoSmithKline \\
\hline Viên nhai & Isentress $\mathbb{R}$ & Raltegravir & Merck \\
\hline
\end{tabular}

Thuốc uống phải thao tác trước khi sử

dụng. Thuốc uống phải thao tác trước khi sử dụng là các dạng bào chế rắn như bột hoặc cốm phải pha chế lại thành dung dịch hoặc hồn dịch, viên sủi bọt, viên nén phân tán trong nước, bột hoăcc viên nang chứa bột thuốc dùng để rắc vào thức ăn mềm và đồ uống... Bột pha dung dịch uống Epaned® (Enalapril maleat) của Silvergate Pharmaceuticals, Inc., bột pha hỗn dịch uống Zmax ${ }^{\circledR}$ (Azithromycin) của Pfizer, viên nén pha hỗn dịch uống Tracleer ${ }^{\circledR}$ (Bosentan) của Actelion Pharmaceuticals, viên nang Tamifluß (Oseltamivir phosphat) của Roche.... Viên nang Tamiflu ${ }^{\circledR}$ có thể được mở ra và trộn với chất lỏng ngọt như si rô dùng đường uống thích hợp cho trẻ em.

\section{MộT SỐ NGHIÊN CỨU VỀ BÀO CHẾ THUỐc UỐNG DÙNG CHO TRẺ EM}

Các nhà nghiên cứu về bào chế đã tập trung nghiên cứu một số biện pháp cải thiện mùi vị cho dạng bào chế rắn dùng đường uống thay vì các dạng bào chế lỏng.

Deng Y. và cộng sự đã bào chế tiểu phân nano hạn chế vị đắng dùng cho trẻ em với hai dược chất là lopinavir và ritonavir. Tiểu phân nano được bào chế bằng phương pháp kết tủa sử dụng chất mang Eudragit EPO. Kết quả của nghiên cứu đã thu được tiểu phân nano với hiệu suất nạp dược chất $98 \%$. Khả năng che vị đắng của hệ tiểu phân nano được đánh giá bằng nghiên cứu trên mô hình lưỡi điện tử. Các hạt nano có thể ăn được và che mùi vị có thể được đưa vào các viên nén nhỏ hoặc màng phim, sử dụng thích hợp cho trẻ em [3].

Nese C. và cộng sự đã nghiên cứu bào chế các loại sữa bò có hàm lượng chất béo khác nhau để cung cấp theophyllin qua đường uống dùng cho trẻ em. Bột được thu được bằng cách sấy phun theophylin được phân tán trong sữa tươi chứa $60 \%$ theophyllin. Tiểu phân bột có hình cầu với kích thước $3,7 \mu \mathrm{m}$ và các hạt phân bố có kích thước hẹp, năng suất cao trên $70 \%$, ổn định trong 6 tháng $\left(25^{\circ} \mathrm{C} /\right.$ độ ẩm $\left.65 \%\right)$ trong bao bì kín. Nghiên cứu cho thấy các chế phẩm thu được từ sữa ít chất béo kém ổn định hơn sữa có hàm lượng chất béo cao. Do đó, sữa tươi có thể được chuyển đổi thành các chế phẩm bột ổn định để điều chế các dạng bào chế rắn/lỏng uống để cung cấp các liều theophyllin dùng cho trẻ em [6].

Almurisi S. H. và cộng sự đã bào chế thạch ăn liên chứa paracetamol dùng cho trẻ em nhằm han chế vị đắng. Paracetamol được bao trong các hạt alginat với lớp ngoài bao chitosan và được rắc lên bột thạch ăn liền với thành phần gồm glycin, carrageena và calci lactat gluconat. Thạch paracetamol dễ dàng phân tán trở lại trong $20 \mathrm{ml}$ nước trong 2 phút để tạo thạch và không có vị đắng [1].

Để hạn chế vị đắng của dược chất, một số tác giả đã nghiên cứu bào chế dạng đồng kết tinh griseofulvin với acesulfame, một chất làm ngọt nhân tạo. Các tinh thể của acesulfame có vị ngọt, dễ chịu hơn saccarose 200 lần. Để cải thiện khả năng chịu nén kém và che vị đắng của paracetamol, các tác giả đã sử dụng trimethylglycin, một chất chuyển hóa của cholin có nhiều trong củ cải đường, cua và tôm.

Công nghệ in 3D là một phương pháp để điêu chế các loại thuốc phù hợp sau khi được FDA phê duyệt viên nén in 3D vào năm 2015. Một chế phẩm thuốc dạng kẹo cao su chứa lamotrigin cho bệnh nhi bằng cách sử dụng công nghệ in $3 \mathrm{D}$ với thành phần bao gồm gelatin, HPMC, si rô và nước. Chế phẩm được đùn từ vòi phun của máy in sinh học 3D dưới áp suất không khí và được dát mỏng từ dưới lên theo quy trình từng lớp. Các thử nghiệm về độ hòa tan cho thấy $85 \%$ thuốc giải phóng trong vòng 15 phút từ hầu hết các công thức nghiên cứu. Các kết quả cho thấy rằng in 3D là một phương pháp hiệu quả để điều chế các công thức thuốc dạng kẹo dẻo với nhiều hình dang, màu sắc khác nhau và giúp cải thiện khả nằng tuân thủ thuốc của bệnh nhi trong các cơ sở lâm sàng trong tương lai [8].

Bên cạnh việc nghiên cứu các dạng bào chế thích hợp dùng cho trẻ em, ngày nay, có nhiều dụng cụ phân liều cho các dạng bào chế lỏng.

Dụng cụ phân liều Medibottle $®$ bao gồm một loại bình sữa trẻ em truyền thống với một bộ phân phối thuốc uống có thể trượt vào ống giữa của bình sữa. Bình được đổ đầy sữa hoặc đồ uống khác và bộ phân phối được đổ đầy liều lượng thuốc cần thiết rồi lắp vào bình. Trong khi em bé đang uống, pít tông phân phối nhanh chóng bị tụt xuống để tạo ra một tia thuốc sau 
mỗi vài ngụm sữa hoặc đồ uống.

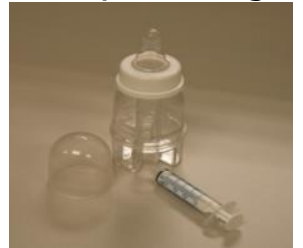

Hinh 4. Binh sữa Medibottle $\mathbb{R}$ (Savi Baby, Mỹ)

"Cốc nuốt viên thuốc" đã được phát triển để giúp những bệnh nhân gặp khó khăn trong việc nuốt viên thuốc. Cốc có nắp đậy và một vòi được thiết kễ đặc biệt. Người dùng đổ đầy nước giải khát vào một nửa cốc, đậy nắp cốc và thả viên thuốc vào vòi. Viên thuốc nằm trên một tấm lưới phía trên chất lỏng. Sau đó người dùng sẽ uống một cách tự nhiên từ cốc. Độ nghiêng và dòng chảy của chất lỏng đẩy viên thuốc xuống phía sau cổ họng để dễ nuốt.

\section{KẾT LUẬN}

Các nhà nghiên cứu phát triển sản phẩm đã ngày càng có nhiều nỗ lực trong việc phát triển các dạng bào chế đường uống dành riêng cho trẻ em. Bên cạnh các dạng thuốc sử dụng ngay như si rô thuổc, hỗn dịch thuốc, viên nén nhỏ, viên nén mini, viên nhai, viên nén phân tán trong miệng, màng phim tan trong miệng còn có các danng thuốc cần phải thao tác trước khi sử dụng như bột hoặc cốm phải pha chế lại thành dung dịch hoặc hỗn dịch, viên sủi bọt, viên nén phân tán trong nước, bột hoặc viên nang chứa bột thuốc dùng để rắc vào thức ăn mềm và đồ uống.

Bên cạnh đó, các nhà nghiên cứu vẫn đang tiếp tục cải tiến trong các chế phẩm dành cho trẻ em qua đường uống. Các biện pháp cải thiện mùi vị của thuốc rắn bằng kỹ thuật tạo hệ tiểu phân nano che vị đắng, đồng kết tinh, bào chế bột thạch hoặc bột sữa chứa dược chất, công nghệ in 3D để bào chế kẹo dẻo chứa dược chất hoặc nghiên cứu các dụng cụ phân liêu thích hợp cho thuốc uống lỏng dùng cho trẻ em.

\section{TÀI LIỆ THAM KHẢO}

1. Almurisi S. H., Doolaanea A. A., et al. (2020), Formulation development of paracetamol instant jelly for pediatric use, Drug development and industrial pharmacy, 46(8), pp. 1373-1383.

2. Comoglu T., Ozyilmaz E.D., (2019), Orally disintegrating tablets and orally disintegrating mini tablets-novel dosage forms for pediatric use, Pharmaceutical Development and technology, 24(7), pp. 902-914.

3. Deng Y., Shen L., Yang Y., et al. (2021), Development of nanoparticle-based orodispersible palatable pediatric formulations, International Journal of Pharmaceutics, 596, pp. 1-9.

4. Meyers R. (2019), A wish list for drug development in pediatrics, Journal of Pharmaceutical Sciences, pp. 1-5.

5. Moreira M., Saraguca M., (2020), How can oral pediatric formulations be improved? A challenge for the XXI century, International Journal of Pharmaceutics, 590, pp. 1-9.

6. Nese C., Palugan L., Cerrea M., et al. (2020), Preparation and characterization of a powder manufactured by spray drying milk based formulations for the delivery of theophylline for pediatric use, International Journal of Pharmaceutics, 580, pp. 1-12.

7. Strickly R. G., (2019), Pediatric oral formulations: An updated review of commercially available pediatric oral formulations since 2007, Journal of Pharmaceutical Sciences, 108, pp. 1335-1365.

8. Tagami T., Ito E., Kida R., et al. (2021), 3D printing of gummy drug formulations composed of gelatin and an HPMC-based hydrogel for pediatric use, International Journal of Pharmaceutics, 594, pp. 1-7.

\section{BIẾN THIÊN NHIP TIM GIẢM LÀ YẾU TỐ NGUY CƠ XUẤT HIÊ̂N RUNG NHĨ MỚI SAU PHẪU THUÂT CẦU NỐI CHỦ VÀNH}

TÓM TẮT

Hệ thống thần kinh tự chủ có vai trò như là yếu tố khởi phát và là nguy cở xuất hiện các rối loạn nhịp

${ }^{1}$ Bênh viên Tim Hà Nôi

Bềnh viền 108

${ }^{3}$ Bềnh viền Bach Mai

Chịu trách nhiệm chính: Ngọ Văn Thanh

Email: ngogiahung@gmail.com

Ngày nhâan bài: 4.01.2021

Ngày phản biên khoa hoc: 3.3.2021

Ngày duyệt bài: 16.3.2021
Ngọ Văn Thanh1, Phạm Trường Sơn², Nguyễn Quang Tuấn ${ }^{3}$ và cs.

tim. Rung nhĩ mới xuất hiện sau phẫu thuật câu nối chủ vành có tỉ lệ $5-40 \%$ tùy theo nghiên cứu. Mối liên quan giữa biến thiên nhịp tim với rung nhĩ xuất hiện sau phấu thuật đã được nghiên cứu với các kết quả khác nhau. Vì vậy, chúng tôi tiến hành nghiên cứu này với mục đích tìm hiểu mối liên quan giữa biến thiên nhịp tim giảm trước phẫu thuật với rung nhĩ mới xuất hiện sau phẫu thuật câuu nối chủ vành. Đối tượng và phương pháp nghiên cứu: tiến cứu mô tả theo dõi dọc 119 đối tượng bệnh có nhịp xoang, được phẫu thuât cầu nối chủ vành có tuần hoàn ngoài cớ thể tai Bệnh viện Tim Hà Nội từ 6/2016 đến 8/2018. Theo dối rung nhî̀ và biến thiên nhịp tim bằng Holter điện tim 